\title{
WNK pathways in cancer signaling networks
}

\author{
Sachith Gallolu Kankanamalage, Aroon S. Karra and Melanie H. Cobb*
}

\begin{abstract}
Background: The with no lysine [K] (WNK) pathway consists of the structurally unique WNK kinases, their downstream target kinases, oxidative stress responsive (OSR) 1 and SPS/Ste20-related proline-alanine-rich kinase (SPAK), and a multitude of OSR1/SPAK substrates including cation chloride cotransporters.

Main body: While the best known functions of the WNK pathway is regulation of ion transport across cell membranes, WNK pathway components have been implicated in numerous human diseases. The goal of our review is to draw attention to how this pathway and its components exert influence on the progression of cancer, specifically by detailing WNK signaling intersections with major cell communication networks and processes.

Conclusion: Here we describe how WNKs and associated proteins interact with and influence PI3K-AKT, TGF- $\beta$, and NF-KB signaling, as well as its unanticipated role in the regulation of angiogenesis.
\end{abstract}

Keywords: WNKS, OSR1, SPAK, STK39, Cellular signaling, lon transport, Cancer, PI3K-AKT, TGF- $\beta$, And NF-KB

\section{Plain English summary}

WNKs are unique signaling kinases that bind and modify a host of cellular proteins to maintain homeostasis. As a consequence, these kinases are involved in the control of cancerous states. To better understand the growing picture of how WNKs affect human disease, we compiled this review to highlight signaling pathways often overlooked in WNK biology.

\section{Background}

The with no lysine [K] (WNK) pathway is an ancient protein kinase signaling axis best known to regulate ion transport across cell membranes in mammals $[1,2]$. However, it is an oversimplification to call this its primary role, or to imply that its role in ion transport regulation is completely understood. WNKs behave in many ways in many contexts, and to date there is no consensus on their general functions. WNKs are members of an unusual serine/ threonine protein kinase family in which the position of the conserved catalytic domain lysine residue necessary for phosphoryl transfer is situated on the glycine-rich loop $[3,4]$. This unique arrangement is accompanied by distinct structural and regulatory properties [5].

An emerging area of study is the dependence of WNK pathway components in the progression of cancer, where

\footnotetext{
* Correspondence: Melanie.Cobb@UTSouthwestern.edu

Department of Pharmacology, The University of Texas Southwestern Medical Center, 6001 Forest Park Road, Dallas, TX 75390-9041, USA
}

the importance of these proteins is highlighted by their malleability. Activated WNK kinases phosphorylate and stimulate OSR1 and SPAK [6-8], serine/threonine kinases that phosphorylate and regulate the activity of a host of protein substrates [9-11] (Fig. 1). The extensive reach of the WNK signaling network encompasses major developmental processes and acute signal responses to changing cellular environments, underscoring the ramifications WNKs and their downstream factors have on disease conditions. Here, to better understand how WNK pathway functions affect cancerous states [12], we examine how WNKs exert regulatory influence on three major cancer-associated signaling networks: PI3K-AKT, TGF- $\beta$, and NF- $k B$ signaling. Finally, we summarize some functions of WNK pathway components in angiogenesis, a process at the heart of cancer progression.

\section{Main text \\ PI3K-AKT}

The PI3K-AKT cascade is a well-studied oncogenic pathway subject to a diverse array of signaling inputs, most prominently insulin, and can influence numerous proteins, including WNK pathway components [13, 14]. In mice, acute insulin treatment results in increased phosphorylation of OSR1, SPAK, and the $\mathrm{NaCl}$ cotransporter (NCC) in the kidney; predictably, this effect is markedly diminished in WNK4 hypomorphic mice $[15,16]$. PI3K-AKT signaling also activates the WNK-OSR1/SPAK-NCC cascade in a 


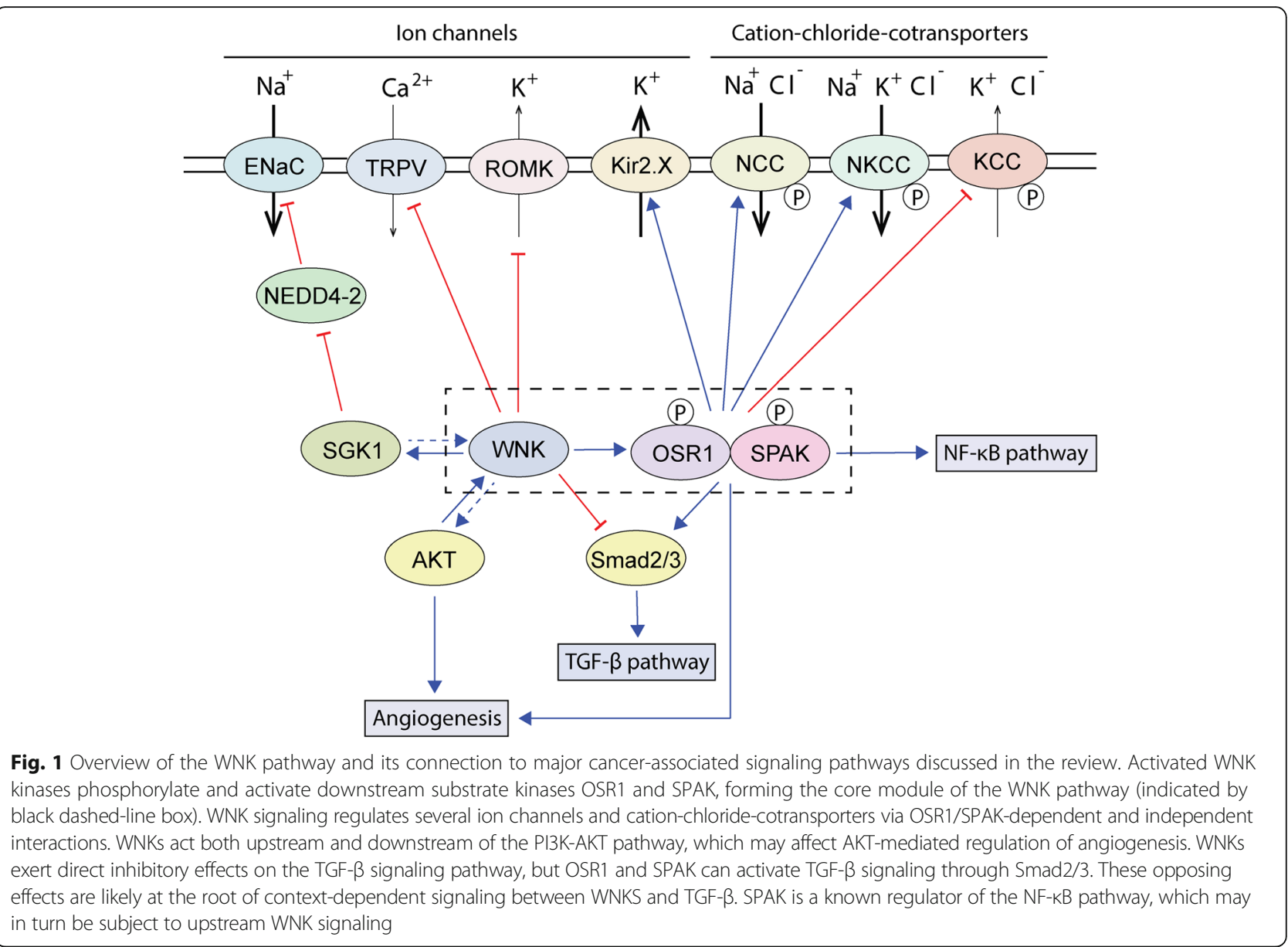

hyperinsulinemic $\mathrm{db} / \mathrm{db}$ mouse model, providing key evidence of AKT-mediated kinase activation of WNKs [17]. AKT directly phosphorylates WNK1 at T60 (T58 in mouse and rat) in vitro, and in cells insulin-like growth factor (IGF)-1 can induce WNK1 T60 phosphorylation. Signaling from IGF-1 to WNK1 is blocked in HEK293 cells via treatment with PI3K inhibitors [18]. A similar relationship is also present in mouse embryonic stem (ES) cells; in ES cells lacking phosphoinositide-dependent kinase (PDK)-1, a protein required for AKT activation, IGF-1 is unable to induce WNK1 T60 phosphorylation $[19,20]$. It is important to note, however, that this phosphorylation has not been shown to affect WNK1 kinase activity directly nor its cellular localization, and may instead influence protein-protein interactions [19]. Another study utilizing a phospho-specific antibody targeting AKT substrate phosphorylation sites following insulin treatment in 3T3-L1 cells identified WNK1 as a putative AKT substrate. Consistent with previous findings, insulin-stimulated phosphorylation of WNK1 is blocked by treatment with PI3K inhibitors and siRNA-mediated depletion of AKT. Although depletion of WNK1 does not affect insulininduced glucose transport, it does increase insulin-induced proliferation of 3T3-L1 preadipocytes [18]. Both AKT and SGK1 phosphorylate WNK1 on this residue, and this phosphorylation is necessary to mediate insulin-induced endocytosis of ROMK [21] as well as for activation of SGK1 and subsequent stimulation of ENaC by WNK1 [22]. AKT-dependent WNK1 phosphorylation and enhanced WNK functions such as increases in phospholipase C- $\beta$ signaling, angiogenesis, and cell migration have been reported by other studies as well [23-27]. Interestingly, WNK3 may also be a direct target of AKT [28]. WNK3 undergoes EGF-dependent phosphorylation in HEK293 cells and this phosphorylation is blocked by wortmannin, implying this is also a PI3K-AKT dependent event. PI3K-AKT signaling also affects the stability of WNK4. AKT phosphorylates Kelch-like 3 (KLHL3), which regulates WNK protein degradation along with Cullin3, a core component of an E3 ubiquitin ligase complex. AKT-mediated phosphorylation of KLHL3 reduces its interaction with WNK4, leading to sustained WNK4 expression [29]. Similar effects are seen with WNK1 and 4 mutations that also result in diminished interactions with KLHL3 and Cullin-3 [30-33].

In addition to acting as a target of the PI3K-AKT pathway, there is some evidence that WNK1 can act upstream 
of AKT. Hypotonic challenges can induce WNK1 T60 phosphorylation and cell proliferation in a rat smooth muscle cell line, and WNK1 overexpression also increases proliferation. WNK1 also increases the hypotonicity- induced activation of AKT and PI3K, whereas the depletion of WNK1 has opposite effects, suggesting that certain hypotonicity-induced cellular effects of WNK1 are mediated through the PI3K-AKT pathway [34] (Fig. 1).

Although currently there are no delineated mechanisms, there is ample evidence that WNK1 is important for cell migration in several cancer types, perhaps via the PI3K-AKT pathway. Acetyl-CoA medium-chain synthetase 3 (ACSM3) is a tumor suppressor in hepatocellular carcinoma (HCC). ACSM3 overexpression inhibits migration and invasion of the HCC cell lines HepG2 and SMMC7721, inhibits cancer metastasis in mouse xenografts, and its loss is associated with poor clinical outcomes [35]. ACSM3 overexpression also decreases the activation of AKT and phosphorylation of WNK1 at T60. Expression of an AKT construct blocked the tumor suppressor effects mediated by ACSM3, making it possible that the AKT-WNK1 axis promotes cell migration and invasion in HCC [27]. In non-small cell lung cancer (NSCLC) cells, the extracellular matrix component secreted protein acidic and rich in cysteine (SPARC) promotes cell migration and epithelial to mesenchymal transition (EMT): SPARC induces AKT activation and increases WNK1 phosphorylation at T60 [36]. Adding some credence to this is the observation that kynurenine (Kyn), which is produced by activated lung fibroblasts, facilitates migration and growth of lung cancer cells and also activates AKT and WNK1-T60 phosphorylation. The depletion of WNK1 in these cells inhibits migration in a manner similar to inhibition of AKT [26]. Because WNK1 T60 phosphorylation has been easier to detect with specific antibodies than activation loop phosphorylation, T60 phosphorylation has often been used as readout for WNK1 activity. It remains to be seen whether this specific post-translational modification directly influences WNK activity in cell migration.

\section{TGF- $\beta$}

WNKs also intersect with the transforming growth factor (TGF) $\beta$ pathway. TGF- $\beta$ has both tumor suppressing and tumor promoting activities, although initial actions are often anti-proliferative [37]. Both WNK1 and WNK4 bind and phosphorylate $\operatorname{Smad} 2 / 3$, the downstream effectors of TGF- $\beta$ signaling, but not Smad1/4. WNK1 depletion in HeLa cells decreases the total amount of Smad2, but increases phosphorylated Smad2 in cell nuclei, thus increasing localized TGF- $\beta$ signaling [38]. Intriguingly, these finding are consistent with the recent discovery that WNK1 depletion increases the expression of TGF- $\beta$ pathway genes in primary human endometrial cells [39].
SPAK mRNA and protein are upregulated in osteosarcoma patient samples, and knockdown of SPAK abolishes proliferation and downregulates invasion in osteosarcoma cell lines. SPAK depletion also decreases the phosphorylation of Smad2/3, suggesting that loss of SPAK antagonizes the tumor-promoting function of the TGF- $\beta$ pathway in osteosarcoma [40]. There is also some evidence that OSR1 is a target of TGF- $\beta$ signaling [41], and taken together these findings point to the high potential for WNK pathway components to influence tumor-related functions TGF- $\beta$ signaling (Fig. 1).

\section{NF-KB signaling and SPAK}

Nuclear factor Kappa B (NF- $\mathrm{kB})$ is a well-known tumor promoter $[42,43]$. Mouse WNK1 has a putative NF- $k B$ site on its promoter, suggesting that WNK1 expression in cells may increase following oncogenic activation [44]. However, within the WNK pathway, SPAK is the best characterized mediator of pro-inflammatory functions in an NF-kB-dependent manner [45] (Fig. 1). The Toll-like receptor 4 , a transmembrane protein that stimulates NF- $\mathrm{KB}$ signaling, is known to lie upstream of SPAKNKCC1 in rat choroid plexus epithelium [46], and may behave as a trigger for regulation of SPAK expression.

TNF- $\alpha$ induces demethylation of the STK39 promoter and increases expression of SPAK in a manner that requires NF-kB binding to STK39; indeed, increased NF-kB enhances the expression of SPAK in cells [47]. SPAK expression is also upregulated by hyperosmotic stress, and this effect is dependent on NF- $\mathrm{kB}$, which displays increased binding to the STK39 promoter [48]. It is also notable that colon-specific (c)SPAK expression is upregulated in patients with ulcerative colitis, an inflammatory bowel disease that can be a contributing factor to colon cancer [49].

The potassium chloride cotransporter, $\mathrm{KCC} 3$, induces the expression of SPAK in cervical cancer cell lines and in HEK293 cells. KCC3 also upregulates NF- $\mathrm{KB}$ and MMP2 in HEK293 cells. It was suggested that NF-kB-induced SPAK activates the $\mathrm{p} 38$ pathway, leading to subsequent activation of MMP2 and promotion of cell invasion, although confirmation of this observation has not been reported. The depletion of SPAK also inhibits growth of xenograft tumors dependent on KCC3, supporting the relevance of SPAK in tumor growth within the context of NF- $\mathrm{kB}$ signaling [45].

SPAK functions not only downstream, but also upstream of NF- $\mathrm{KB}$ signaling, as mesangial cells primed with IgA immune complexes of SPAK knockout mice have decreased NF- $\kappa B$ and $p 38$ signaling [50]. SPAK induces the production of pro-inflammatory cytokines, and SPAK knockout mice lack intestinal and renal inflammation and pro-inflammatory cytokine secretion compared to control mice [50-52]. However, SPAK is also activated by endotoxin and promotes nitric oxide production in mice [53]. SPAK increases the production 
of the anti-inflammatory cytokine interleukin 10 in $\mathrm{T}$ cells, leaving several open questions about the inflammatory consequences of SPAK activation [54, 55] (Fig. 1).

\section{Angiogenesis}

Several components of the WNK pathway are implicated in angiogenesis, a process enhanced in many cancers to maintain blood flow to newly formed tumor tissue [12]. WNK1 knockout mice die before embryonic day 13 and display gross defects in cardiovascular development [56, 57]. Endothelial-specific WNK1 knockout mice also die mid-gestation with similar cardiovascular defects, consistent with the notion that WNK1-induced lethality is a result of failed development of the cardiovascular system and defective angiogenesis [57]. Whole body and endothelial-specific OSR1 knockout mice also fail to develop with similar cardiovascular and angiogenesis defects. Transgenic expression of an active mutant of human OSR1 in a mouse whole-body WNK1 knockout background rescues the developmental defects caused by the loss of WNK1, substantiating the importance of the WNK1-OSR1 axis in cardiovascular development [58].

Work done in our laboratory on cell lines and primary human endothelial cells has shown that WNK1 and OSR1 are required for angiogenesis in vitro. Depletion of WNK1 by siRNA inhibits cord formation in angiogenesis assays and also negatively affects cell proliferation and migration. Notably, WNK1 depletion leads to an anti-migratory gene expression pattern comprising inhibited expression of the mesenchymal transcription factors Slug, ZEB1, MMP2 and MMP9, and increased expression of thrombospondin-1. The depletion of OSR1 and of SPAK have different effects on endothelial cells: OSR1 is necessary for migration, whereas SPAK is necessary for proliferation. Interestingly, exogenous expression of Slug in WNK1-depleted cells partially rescues migration and endothelial cord formation, indicating WNK1 can act via OSR1, SPAK, and Slug to regulate angiogenesis [59] (Fig. 1).

In zebrafish, WNK1 depletion also blocks angiogenesis, indicating that its function in this process is conserved across species. Aberrations in zebrafish angiogenesis caused by the loss of vascular endothelial growth factor receptor (VEGFR)-2 can be partially rescued by ectopic expression of WNK1, although mutation of an AKT phosphorylation site on WNK1 (T60) blocks this partial rescue phenotype. Both VEGFR-2 and VEGFR-3 positively regulate the expression of WNK1a, one of the two major WNK1 isoforms in zebrafish, suggesting VEGFR pathway effects on angiogenesis promotion are enhanced in part through WNK1 [25] (Fig. 1).

\section{Conclusions and future directions}

The WNK signaling axis is an ancient pathway that has been expanded, repurposed, and utilized in numerous contexts over evolutionary time. The need to learn more about its functions in cancer progression, in contrast, is a much more recent development. Currently, there are no clinically-approved drugs that target the WNK pathway being used to treat cancer. But given their unique structural organization, WNKs are attractive drug targets that may hold future promise [60, 61]; indeed, Yamada et al. have recently discovered an orally bioavailable pan-WNK inhibitor [61, 62]. A major challenge moving forward will be identifying reagents that are able to better discriminate specific phosphorylation events as well as WNK isoforms, due to the large number of signaling pathways involving WNKs. Compounds that inhibit OSR1 and SPAK activity have already shown promise as potential anti-cancer drugs [63-66]: Closantel, a SPAK inhibitor, inhibits cancer growth and angiogenesis when tested in a zebrafish model [65, 66], and Rafoxanide, another OSR1/SPAK inhibitor, inhibits CDK4/6 and is proposed as a potential therapeutic for skin cancer [63, 64]. Compounds that block binding between the RFXV/I motifs contained on WNKs and conserved C-terminal domains of OSR1/SPAK also hold promise as therapeutic interventions to inhibit the WNK pathway [60]. Notably, Mori et al. have discovered two such compounds, STOCK1S-50699 and STOCK2S26016, that block these types of interactions [67]. This pharmacological evidence suggests the potential of targeting the WNK pathway in cancer.

While WNKs underlie several regulatory processes and phenomena, our goal in focusing on cancer signaling and angiogenesis was to provide a focused resource on an important emerging area of research. However, even through the lens of cancer progression, our current understanding of WNKs and their downstream targets make it clear that these factors display broad importance for cohesive cellular signaling and regulation.

\section{Abbreviations}

ACSM3: Acetyl-CoA medium-chain synthetase 3; AKT: Protein Kinase B; EGF: Epidermal growth factor; EMT: Epithelial to mesenchymal transition; ENaC: Epithelial sodium channel; ES cells: Embryonic stem cells;

HCC: Hepatocellular carcinoma; HEK293: Human embryonic kidney 293; IgA: Immunoglobulin A; IGF: Insulin-like growth factor; KCC3: Potassiumchloride cotransporter 3; KLHL: Kelch-like; Kyn: Kynurenine; MMP2: Matrix metalloproteinase 2; NCC: Sodium-chloride cotransporter; NF-KB: Nuclear factor Kappa B; NKCC1: Sodium-potassium-chloride cotransporter;

NSCLC: Non-small cell lung cancer; OSR1: Oxidative stress responsive 1; PDK: Phosphoinositide-dependent kinase; PI3K: Phosphatidylinositol 3-kinase; ROMK: Renal outer medullary potassium channel; SGK: Serum/glucocorticoid regulated kinase; SPAK: SPS/Ste20-related proline-alanine-rich kinase;

SPARC: Secreted protein acidic and rich in cysteine; STK39: Serine/Threonine kinase 39; TGF: Transforming growth factor; TNF-a: Tumor necrosis factor- $a_{\text {; }}$ VEGFR: Vascular endothelial growth factor receptor; WNK: with no lysine [K]; ZEB1: Zinc finger E-box-binding homeobox 1

\section{Acknowledgements}

The authors would like to thank all members of the Cobb Laboratory for their invaluable input and suggestions, and Dionne Ware for administrative assistance.

Funding

Welch Foundation 11243. 


\section{Availability of data and materials}

Not applicable.

\section{Authors' contributions}

S.G.K. is the primary author of the manuscript and composed the majority of the work. Parts of the manuscript were developed from Chapter 1 of S.G.K's doctoral dissertation. A.S.K. edited and compiled the sections, and the whole work was thoroughly supervised by M.H.C. All authors read and approved the final manuscript.

\section{Ethics approval and consent to participate}

Not applicable.

\section{Consent for publication}

Not applicable.

\section{Competing interests}

The authors declare that they have no competing interest.

\section{Publisher's Note}

Springer Nature remains neutral with regard to jurisdictional claims in published maps and institutional affiliations.

Received: 23 August 2018 Accepted: 22 October 2018 Published online: 03 November 2018

\section{References}

1. Gagnon KB, England R, Delpire E. Volume sensitivity of cation-cl-cotransporters is modulated by the interaction of two kinases: Ste20-related proline-alaninerich kinase and WNK4. Am J Physiol Cell Physiol. 2006;290(1):C134-42.

2. Huang $\mathrm{CL}$, Cha SK, Wang HR, Xie J, Cobb MH. WNKs: protein kinases with a unique kinase domain. Exp Mol Med. 2007;39(5):565-73.

3. Xu B, English JM, Wilsbacher JL, Stippec S, Goldsmith EJ, Cobb MH. WNK1, a novel mammalian serine/threonine protein kinase lacking the catalytic lysine in subdomain II. J Biol Chem. 2000;275(22):16795-801.

4. Verissimo F, Jordan P. WNK kinases, a novel protein kinase subfamily in multi-cellular organisms. Oncogene. 2001;20(39):5562-9.

5. Piala AT, Moon TM, Akella R, He H, Cobb MH, Goldsmith EJ. Chloride sensing by WNK1 involves inhibition of autophosphorylation. Sci Signal. 2014;7(324):ra41.

6. Moriguchi T, Urushiyama S, Hisamoto N, lemura S, Uchida S, Natsume T, et al. WNK1 regulates phosphorylation of cation-chloride-coupled cotransporters via the STE20-related kinases, SPAK and OSR1. J Biol Chem. 2005:280(52):42685-93.

7. Vitari AC, Deak M, Morrice NA, Alessi DR. The WNK1 and WNK4 protein kinases that are mutated in Gordon's hypertension syndrome phosphorylate and activate SPAK and OSR1 protein kinases. The Biochemical journal. 2005; 391(Pt 1):17-24.

8. Anselmo AN, Earnest S, Chen W, Juang YC, Kim SC, Zhao Y, et al. WNK1 and OSR1 regulate the $\mathrm{Na}+, \mathrm{K}+, 2 \mathrm{Cl}$ - cotransporter in HeLa cells. Proc Natl Acad Sci U S A. 2006;103(29):10883-8.

9. Piechotta K, Lu J, Delpire E. Cation chloride cotransporters interact with the stress-related kinases Ste20-related proline-alanine-rich kinase (SPAK) and oxidative stress response 1 (OSR1). J Biol Chem. 2002;277(52):50812-9.

10. Dowd BF, Forbush B. PASK (proline-alanine-rich STE20-related kinase), a regulatory kinase of the Na-K-Cl cotransporter (NKCC1). J Biol Chem. 2003; 278(30):27347-53.

11. Vitari AC, Thastrup J, Rafiqi FH, Deak M, Morrice NA, Karlsson HK, et al. Functional interactions of the SPAK/OSR 1 kinases with their upstream activator WNK1 and downstream substrate NKCC1. Biochem J. 2006;397(1):223-31.

12. Hanahan D, Weinberg RA. Hallmarks of cancer: the next generation. Cell. 2011;144(5):646-74.

13. Martini M, De Santis MC, Braccini L, Gulluni F, Hirsch E. PI3K AKT signaling pathway and cancer: an updated review. Ann Med. 2014;46(6):372-83.

14. Mayer IA, Arteaga CL. The PI3K/AKT pathway as a target for Cancer treatment. Annu Rev Med. 2016:67:11-28.

15. Komers R, Rogers S, Oyama T, Xu B, Yang CL, McCormick J, et al. Enhanced phosphorylation of $\mathrm{Na}(+)$-cl- co-transporter in experimental metabolic syndrome: role of insulin. Clin Sci. 2012;123(11):635-47.
16. Sohara E, Rai T, Yang SS, Ohta A, Naito S, Chiga M, et al. Acute insulin stimulation induces phosphorylation of the Na-cl cotransporter in cultured distal mpkDCT cells and mouse kidney. PLoS One. 2011;6(8):e24277.

17. Nishida H, Sohara E, Nomura N, Chiga M, Alessi DR, Rai T, et al. Phosphatidylinositol 3-kinase/Akt signaling pathway activates the WNKOSR1/SPAK-NCC phosphorylation cascade in hyperinsulinemic $\mathrm{db} / \mathrm{db}$ mice. Hypertension. 2012;60(4):981-90.

18. Jiang ZY, Zhou QL, Holik J, Patel S, Leszyk J, Coleman K, et al. Identification of WNK1 as a substrate of Akt/protein kinase $B$ and a negative regulator of insulinstimulated mitogenesis in 3T3-L1 cells. J Biol Chem. 2005;280(22):21622-8.

19. Vitari AC, Deak M, Collins BJ, Morrice N, Prescott AR, Phelan A, et al. WNK1, the kinase mutated in an inherited high-blood-pressure syndrome, is a novel PKB (protein kinase B)/Akt substrate. Biochem J. 2004:378(Pt 1):257-68.

20. Toker A, Newton AC. Cellular signaling: pivoting around PDK-1. Cell. 2000; 103(2):185-8.

21. Cheng CJ, Huang CL. Activation of PI3-kinase stimulates endocytosis of ROMK via Akt1/SGK1-dependent phosphorylation of WNK1. J Am Soc Nephrol. 2011;22(3):460-71

22. Xu BE, Stippec S, Lazrak A, Huang CL, Cobb MH. WNK1 activates SGK1 by a phosphatidylinositol 3-kinase-dependent and non-catalytic mechanism. J Biol Chem. 2005;280(40):34218-23.

23. Sale EM, Hodgkinson CP, Jones NP, Sale GJ. A new strategy for studying protein kinase $B$ and its three isoforms. Role of protein kinase $B$ in phosphorylating glycogen synthase kinase-3, tuberin, WNK1, and ATP citrate lyase. Biochemistry. 2006;45(1):213-23.

24. An SW, Cha SK, Yoon J, Chang S, Ross EM, Huang CL. WNK1 promotes PIP(2) synthesis to coordinate growth factor and GPCR-Gq signaling. Curr Biol. 2011:21(23):1979-87.

25. Lai JG, Tsai SM, Tu HC, Chen WC, Kou FJ, Lu JW, et al. Zebrafish WNK lysine deficient protein kinase 1 (wnk1) affects angiogenesis associated with VEGF signaling. PLoS One. 2014;9(8):e106129.

26. Hsu YL, Hung JY, Chiang SY, Jian SF, Wu CY, Lin YS, et al. Lung cancerderived galectin-1 contributes to cancer associated fibroblast-mediated cancer progression and immune suppression through TDO2/kynurenine axis. Oncotarget. 2016;7(19):27584-98

27. Ruan HY, Yang C, Tao XM, He J, Wang T, Wang H, et al. Downregulation of ACSM3 promotes metastasis and predicts poor prognosis in hepatocellular carcinoma. Am J Cancer Res. 2017:7(3):543-53.

28. Garzon-Muvdi T, Schiapparelli P, Ap Rhys C, Guerrero-Cazares H, Smith C, $\mathrm{Kim} \mathrm{DH}$, et al. Regulation of brain tumor dispersal by NKCC1 through a novel role in focal adhesion regulation. PLoS Biol. 2012;10(5):e1001320.

29. Yoshizaki Y, Mori Y, Tsuzaki Y, Mori T, Nomura N, Wakabayashi M, et al. Impaired degradation of WNK by Akt and PKA phosphorylation of KLHL3. Biochem Biophys Res Commun. 2015;467(2):229-34.

30. Boyden LM, Choi M, Choate KA, Nelson-Williams CJ, Farhi A, Toka HR, et al, Mutations in kelch-like 3 and cullin 3 cause hypertension and electrolyte abnormalities. Nature. 2012:482(7383):98-102.

31. Louis-Dit-Picard H, Barc J, Trujillano D, Miserey-Lenkei S, Bouatia-Naji N, Pylypenko O, et al. KLHL3 mutations cause familial hyperkalemic hypertension by impairing ion transport in the distal nephron. Nat Genet. 2012:44(4):456-60 S1-3.

32. McCormick JA, Yang CL, Zhang C, Davidge B, Blankenstein Kl, Terker AS, et al. Hyperkalemic hypertension-associated cullin 3 promotes WNK signaling by degrading KLHL3. J Clin Invest. 2014;124(11):4723-36.

33. Ohta A, Schumacher FR, Mehellou Y, Johnson C, Knebel A, Macartney TJ, et al. The CUL3-KLHL3 E3 ligase complex mutated in Gordon's hypertension syndrome interacts with and ubiquitylates WNK isoforms: disease-causing mutations in KLHL3 and WNK4 disrupt interaction. The Biochemical journal. 2013;451(1):111-22.

34. Zhang YJ, Zheng HQ, Chen BY, Sun L, Ma MM, Wang GL, et al. WNK1 is required for proliferation induced by hypotonic challenge in rat vascular smooth muscle cells. Acta Pharmacol Sin. 2017.

35. Gopal R, Selvarasu K, Pandian PP, Ganesan K. Integrative transcriptome analysis of liver cancer profiles identifies upstream regulators and clinical significance of ACSM3 gene expression. Cell Oncol. 2017;40(3):219-33.

36. Hung JY, Yen MC, Jian SF, Wu CY, Chang WA, Liu KT, et al. Secreted protein acidic and rich in cysteine (SPARC) induces cell migration and epithelial mesenchymal transition through WNK1/snail in non-small cell lung cancer. Oncotarget. 2017;8(38):63691-702.

37. Massague J, Blain SW, Lo RS. TGFbeta signaling in growth control, cancer, and heritable disorders. Cell. 2000;103(2):295-309. 
38. Lee BH, Chen W, Stippec S, Cobb MH. Biological cross-talk between WNK1 and the transforming growth factor beta-Smad signaling pathway. J Biol Chem. 2007;282(25):17985-96.

39. Adams NR, Vasquez YM, Mo Q, Gibbons W, Kovanci E, DeMayo FJ. WNK lysine deficient protein kinase 1 regulates human endometrial stromal cell decidualization, proliferation, and migration in part through mitogenactivated protein kinase 7. Biol Reprod. 2017;97(3):400-12.

40. Huang T, Zhou Y, Cao Y, Tao J, Zhou ZH, Hang DH. STK39, overexpressed in osteosarcoma, regulates osteosarcoma cell invasion and proliferation. Oncol Lett. 2017;14(4):4599-604.

41. Barrios-Rodiles M, Brown KR, Ozdamar B, Bose R, Liu Z, Donovan RS, et al. High-throughput mapping of a dynamic signaling network in mammalian cells. Science. 2005;307(5715):1621-5.

42. Karin M. NF-kappaB as a critical link between inflammation and cancer. Cold Spring Harb Perspect Biol. 2009;1(5):a000141.

43. Hoesel B, Schmid JA. The complexity of NF-kappaB signaling in inflammation and cancer. Mol Cancer. 2013;12:86.

44. Zeng G, Gao L, Xia T, Gu Y, Yu RK. Expression of the mouse WNK1 gene in correlation with ganglioside GD3 and functional analysis of the mouse WNK1 promoter. Gene. 2005;344:233-9.

45. Chiu MH, Liu HS, Wu YH, Shen MR, Chou CY. SPAK mediates KCC3enhanced cervical cancer tumorigenesis. FEBS J. 2014;281(10):2353-65.

46. Karimy JK, Zhang J, Kurland DB, Theriault BC, Duran D, Stokum JA, et al. Inflammation-dependent cerebrospinal fluid hypersecretion by the choroid plexus epithelium in posthemorrhagic hydrocephalus. Nat Med. 2017;23(8): 997-1003.

47. Yan Y, Dalmasso G, Nguyen HT, Obertone TS, Charrier-Hisamuddin L, Sitaraman SV, et al. Nuclear factor-kappaB is a critical mediator of Ste20-like proline-/alanine-rich kinase regulation in intestinal inflammation. Am J Pathol. 2008;173(4):1013-28.

48. Yan Y, Dalmasso G, Nguyen HT, Obertone TS, Sitaraman SV, Merlin D. Ste20related proline/alanine-rich kinase (SPAK) regulated transcriptionally by hyperosmolarity is involved in intestinal barrier function. PLoS One. 2009; 4(4):e5049.

49. Yan Y, Nguyen H, Dalmasso G, Sitaraman SV, Merlin D. Cloning and characterization of a new intestinal inflammation-associated colonic epithelial Ste20-related protein kinase isoform. Biochim Biophys Acta. 2007;1769(2):106-16.

50. Lin TJ, Yang SS, Hua KF, Tsai YL, Lin SH, Ka SM. SPAK plays a pathogenic role in IgA nephropathy through the activation of NF-kappaB/MAPKs signaling pathway. Free Radic Biol Med. 2016:99:214-24.

51. Yan Y, Laroui H, Ingersoll SA, Ayyadurai S, Charania M, Yang S, et al. Overexpression of Ste20-related proline/alanine-rich kinase exacerbates experimental colitis in mice. J Immunol. 2011;187(3):1496-505.

52. Zhang Y, Viennois E, Xiao B, Baker MT, Yang S, Okoro I, et al. Knockout of Ste20-like proline/alanine-rich kinase (SPAK) attenuates intestinal inflammation in mice. Am J Pathol. 2013;182(5):1617-28.

53. Shih CC, Hsu LP, Liao MH, Yang SS, Ho ST, Wu CC. Effects of SPAK on vascular reactivity and nitric oxide production in endotoxemic mice. Eur J Pharmacol. 2017.

54. Cardone J, Le Friec G, Vantourout P, Roberts A, Fuchs A, Jackson I, et al. Complement regulator CD46 temporally regulates cytokine production by conventional and unconventional T cells. Nat Immunol. 2010;11(9):862-71.

55. Couper KN, Blount DG, Riley EM. IL-10: the master regulator of immunity to infection. J Immunol. 2008;180(9):5771-7.

56. Zambrowicz BP, Abuin A, Ramirez-Solis R, Richter LJ, Piggott J, BeltrandelRio $\mathrm{H}$, et al. Wnk1 kinase deficiency lowers blood pressure in mice: a gene-trap screen to identify potential targets for therapeutic intervention. Proc Natl Acad Sci U S A. 2003;100(24):14109-14.

57. Xie J, Wu T, Xu K, Huang IK, Cleaver O, Huang CL. Endothelial-specific expression of WNK1 kinase is essential for angiogenesis and heart development in mice. Am J Pathol. 2009;175(3):1315-27.

58. Xie J, Yoon J, Yang SS, Lin SH, Huang CL. WNK1 protein kinase regulates embryonic cardiovascular development through the OSR1 signaling cascade. J Biol Chem. 2013;288(12):8566-74.

59. Dbouk HA, Weil LM, Perera GK, Dellinger MT, Pearson G, Brekken RA, et al. Actions of the protein kinase WNK1 on endothelial cells are differentially mediated by its substrate kinases OSR1 and SPAK. Proc Natl Acad Sci U S A. 2014;111(45):15999-6004.

60. Alessi DR, Zhang J, Khanna A, Hochdorfer T, Shang Y, Kahle KT. The WNKSPAK/OSR1 pathway: master regulator of cation-chloride cotransporters. Sci Signal. 2014;7(334):re3.
61. Zhang J, Deng X, Kahle KT. Leveraging unique structural characteristics of WNK kinases to achieve therapeutic inhibition. Sci Signal. 2016;9(450):e3.

62. Yamada K, Park HM, Rigel DF, DiPetrillo K, Whalen EJ, Anisowicz A, et al. Small-molecule WNK inhibition regulates cardiovascular and renal function. Nat Chem Biol. 2016;12(11):896-8.

63. AlAmri MA, Kadri H, Alderwick LJ, Simpkins NS, Mehellou Y. Rafoxanide and Closantel inhibit SPAK and OSR1 kinases by binding to a highly conserved allosteric site on their C-terminal domains. ChemMedChem. 2017;12(9):639-45.

64. Shi X, Li H, Shi A, Yao H, Ke K, Dong C, et al. Discovery of rafoxanide as a dual CDK4/6 inhibitor for the treatment of skin cancer. Oncol Rep. 2018; 40(3):1592-600

65. Kikuchi E, Mori T, Zeniya M, Isobe K, Ishigami-Yuasa M, Fujii S, et al. Discovery of novel SPAK inhibitors that block WNK kinase signaling to Cation chloride transporters. J Am Soc Nephrol. 2015;26(7):1525-36.

66. Zhu XY, Xia B, Liu HC, Xu YQ, Huang CJ, Gao JM, et al. Closantel Suppresses Angiogenesis and Cancer Growth in Zebrafish Models. Assay Drug Dev Technol. 2016

67. Mori T, Kikuchi E, Watanabe Y, Fujii S, Ishigami-Yuasa M, Kagechika H, et al. Chemical library screening for WNK signalling inhibitors using fluorescence correlation spectroscopy. Biochem J. 2013;455(3):339-45.

\section{Ready to submit your research? Choose BMC and benefit from:}

- fast, convenient online submission

- thorough peer review by experienced researchers in your field

- rapid publication on acceptance

- support for research data, including large and complex data types

- gold Open Access which fosters wider collaboration and increased citations

- maximum visibility for your research: over $100 \mathrm{M}$ website views per year

At BMC, research is always in progress.

Learn more biomedcentral.com/submissions 